\title{
Recognition of extracellular bacteria by NLRs and its role in the development of adaptive immunity
}

\section{Jonathan Ferrand and Richard Louis Ferrero*}

Centre for Innate Immunity and Infectious Diseases, Monash Institute of Medical Research, Monash University, Clayton, VIC, Australia

Edited by:

Jorg Hermann Fritz, McGill University, Canada

\section{Reviewed by:}

Annapurna Nayak, Brunel University, UK

Fayyaz S. Sutterwala, University of lowa, USA

\section{*Correspondence:}

Richard Louis Ferrero, Centre for Innate Immunity and Infectious

Diseases, Monash Institute of

Medical Research, Monash

University, 27-31 Wright Street,

Clayton, VIC 3168, Australia

e-mail: richard.ferrero@monash.edu
Innate immune recognition of bacteria is the first requirement for mounting an effective immune response able to control infection. Over the previous decade, the general paradigm was that extracellular bacteria were only sensed by cell surface-expressed Toll-like receptors (TLRs), whereas cytoplasmic sensors, including members of the Nod-like receptor (NLR) family, were specific to pathogens capable of breaching the host cell membrane. It has become apparent, however, that intracellular innate immune molecules, such as the NLRs, play key roles in the sensing of not only intracellular, but also extracellular bacterial pathogens or their components. In this review, we will discuss the various mechanisms used by bacteria to activate NLR signaling in host cells. These mechanisms include bacterial secretion systems, pore-forming toxins, and outer membrane vesicles. We will then focus on the influence of NLR activation on the development of adaptive immune responses in different cell types.

Keywords: NLRs, extracellular bacteria, OMVs, adaptive immunity, innate immunity

\section{INTRODUCTION}

A balanced relationship between humans and their microbiota is required for a variety of biological functions, including optimal protection against invasion by microbial pathogens, development of the mucosal immune system, and control of metabolic processes [reviewed in Ref. (1)]. The ability of the host immune system to distinguish between commensals and pathogens is required to avoid the development of persistent immune responses against the normal microbiota, yet maintain appropriate immune responses to pathogens. However, bacterial pathogens are able to avoid or subvert the host immune system to promote their survival and colonization. To this end, bacteria can either secrete different components into the extracellular medium or inject molecules into the host cell cytoplasm. In parallel, host cells have developed a wide range of pattern-recognition receptors (PRRs), including Toll-like receptors (TLRs) and Nod-like receptors (NLRs), to detect microorganism- and/or danger-associated molecular patterns (MAMPS and DAMPS, respectively) present in the extracellular medium or in their cytoplasm. MAMPS include virulence factors, but also essential components of both commensals and pathogens, e.g., lipopolysaccharide (LPS), peptidoglycan, or nucleic acids. Recent studies have shown that the recognition of the microbiota that takes place in the gut is necessary for the development of a normal epithelium, by controlling the balance of proliferation and differentiation, as well as maintaining a properly functioning immune system $(1,2)$.

Over the previous decade, the general paradigm was that extracellular bacteria were only sensed by cell surface-expressed TLRs, whereas cytoplasmic sensors, including members of the NLR family, were specific to pathogens capable of breaching the host cell membrane. Structurally, NLRs share a typical tripartite architecture with a conserved central nucleotide-binding domain, which restrains the catalytic activity of NLR family proteins. This central domain is named NACHT after the original proteins which defined the features of this domain: neuronal apoptosis inhibitory protein (NAIP), MHC class II transcription activator (CIITA), incompatibility locus protein from Podospora anserine (HET-E), and a telomerase-associated protein (TP1). At the C-terminal region of NLR proteins are a series of leucine-rich repeats (LRRs) that are believed to initiate NLR activation after recognition of the appropriate signal, although this mechanism is still unclear (3). The N-terminal effector domain, which specifies the function of NLRs, is less conserved. Indeed, NLRs may harbor either a pyrin domain (PYD), a caspase-activation and recruitment domain (CARD), a baculovirus inhibitor of apoptosis domain (BIR), or an as yet characterized domain (Table 1) (4). To date, 23 NLR family members have been reported, each playing different roles in pathogen recognition, homeostasis, apoptosis, or gut development [reviewed in Ref. (4)]. In the context of host-pathogen responses, NLR activation has been shown to induce the production of pro-inflammatory effectors through either nuclear translocation of Nuclear Factor- $\mathrm{\kappa B}$ (NF- $\mathrm{KB}$ ) or formation of highmolecular-weight platforms, named inflammasomes, which activate caspase- 1 . The main substrates of caspase- 1 are cytokine proforms of IL-1 $\beta$ and IL-18, which are usually expressed in an NF$\kappa \mathrm{B}$-dependent manner. Hence, to be expressed in a fully mature form, these cytokines require regulation at both transcriptional and post-transcriptional levels. Several distinct inflammasomes have been described in the literature, consisting of different scaffolding proteins of the NLR or the PYHIN (PYRIN and HIN-200) superfamilies [reviewed in Ref. (5)].

Despite their intracellular localization, it has become apparent that NLRs play key roles in the sensing of not only intracellular, but also extracellular bacterial pathogens or their components. In this review, we will summarize the mechanisms used by extracellular pathogens to deliver bacterial components into host cells and how 
Table 1 | NLR family members and bacterial recognition.

\begin{tabular}{|c|c|c|c|c|c|}
\hline Effector domain & NLR family member & Bacteria & NLRs ligands & Activation mechanism & Reference \\
\hline \multirow[t]{9}{*}{ CARD } & NOD1 & H. pylori & Peptidoglycan & T4SS & Viala et al. (6) \\
\hline & & H. pylori & Peptidoglycan & OMVs & Kaparakis et al. (7), Bielig et al. (8), \\
\hline & & N. gonorrhoeae & & & \\
\hline & & V. cholerae & & & \\
\hline & & B. pseudomallei & BsaK & & \\
\hline & & E. coli & EprJ, Escl & & \\
\hline & & S. flexneri & Mxil & & \\
\hline & & P. aeruginosa & Pscl & & \\
\hline & NLRC4/NAIP5 ${ }^{a}$ & S. typhimurium & Flagellin & T3SS & Kofoed and Vance (11), Zhao et al. (12) \\
\hline \multirow{9}{*}{ PYR } & & L. monocytogenes & Listeriolysin $\mathrm{O}$ & $\mathrm{PFT}$ & Gurcel et al. (16), Mariathasan et al. \\
\hline & & S. aureus & Hemolysins and PVL & & (17), Harder et al. (18), Munoz-Planillo \\
\hline & & A. hydrophila & Aerolysin & & et al. (19), Dunne et al. (20), McCoy et \\
\hline & & A. veronii & Aerolysin & & al. (21), McCoy et al. (22), McNeela et \\
\hline & & B. pertussis & CyaA & & al. (23), Kebaier et al. (24), Holzinger et \\
\hline & & S. pneumoniae & Pneumolysin & & al. (25) \\
\hline & & S. pyogenes & Streptolysin O & & \\
\hline & & V. vulnificus & HlyA & & \\
\hline & & V. cholerae & MARTX & & \\
\hline
\end{tabular}

BYR

NLRP1

B. anthracis

Anthrax lethal toxin

Boyden and Dietrich (26)

NLR family members are classified depending on the function of the N-terminal effector domain: CARD, caspase-activation and recruitment domain; PYD, pyrin domain; BIR, baculovirus inhibitor domain.

alndicates that proteins are expressed in mice only. The ligands and the activation mechanisms are detailed in the text.

infections by these microorganisms are sensed via NLRs. Lastly, we will discuss the importance of the activation of innate immunity receptors, such as NLRs, in tailoring an appropriate adaptive immune response.

\section{MECHANISMS WHEREBY BACTERIAL COMPONENTS GAIN ACCESS TO THE CYTOPLASM \\ BACTERIAL SECRETION SYSTEMS}

Bacteria that need to deliver their effectors across both bacterial and cell membranes have developed highly specialized secretion systems to reach their cytoplasmic targets. Among the six described secretion systems, the injection of bacterial components through either type- 3 or type- 4 secretion systems (T3SS and T4SS, respectively) has been reported to result in the activation of NLR signaling in host cells (Figure 1).

The T3SS, or "injectisome," is a specialized molecular machine which is closely related to the bacterial flagellar apparatus. T3SSs have been identified in numerous Gram-negative bacteria, including pathogens, symbionts, and commensals, suggesting that the T3SS is not a hallmark of pathogenic microorganisms [reviewed in Ref. (27) and (28)]. The global architecture of injectisomes is conserved between bacteria and comprises a needle complex, composed of two pairs of rings that are connected by a rod, spanning the inner and outer bacterial membranes. This structure has at its end a hollow needle, a filament, or a pilus. The main function of T3SSs is to deliver effector proteins across the membranes of host cells, in which these molecules are able to activate cell signaling pathways.

Similarly, T4SSs are specialized macromolecular machines that can deliver DNA and/or proteins to host cells. In contrast to T3SSs, however, those of the type- 4 family are believed to be related to bacterial conjugation systems, rather than the flagellar apparatus. T4SSs have been identified in many Gram-negative and -positive bacteria, as the complex can span both types of membrane [reviewed in Ref. (28) and (29)]. T4SSs are classified as Type A or B, depending on structure composition, but both aim to deliver bacterial effectors to host cells. The Type A T4SSs are defined by their homology with the VirB/D4 system of the plant pathogen Agrobacterium tumefaciens, whereas the Type B T4SSs are closer to the conjugal transfer systems of the self-transmissible IncI plasmid (29).

The first study to report a mechanism for the recognition of extracellular bacteria by intracellular receptors was described by Viala et al. who showed how virulent Helicobacter pylori strains are able to activate the cytosolic NLR family member, nucleotidebinding oligomerization domain-containing protein 1 (NOD1) 


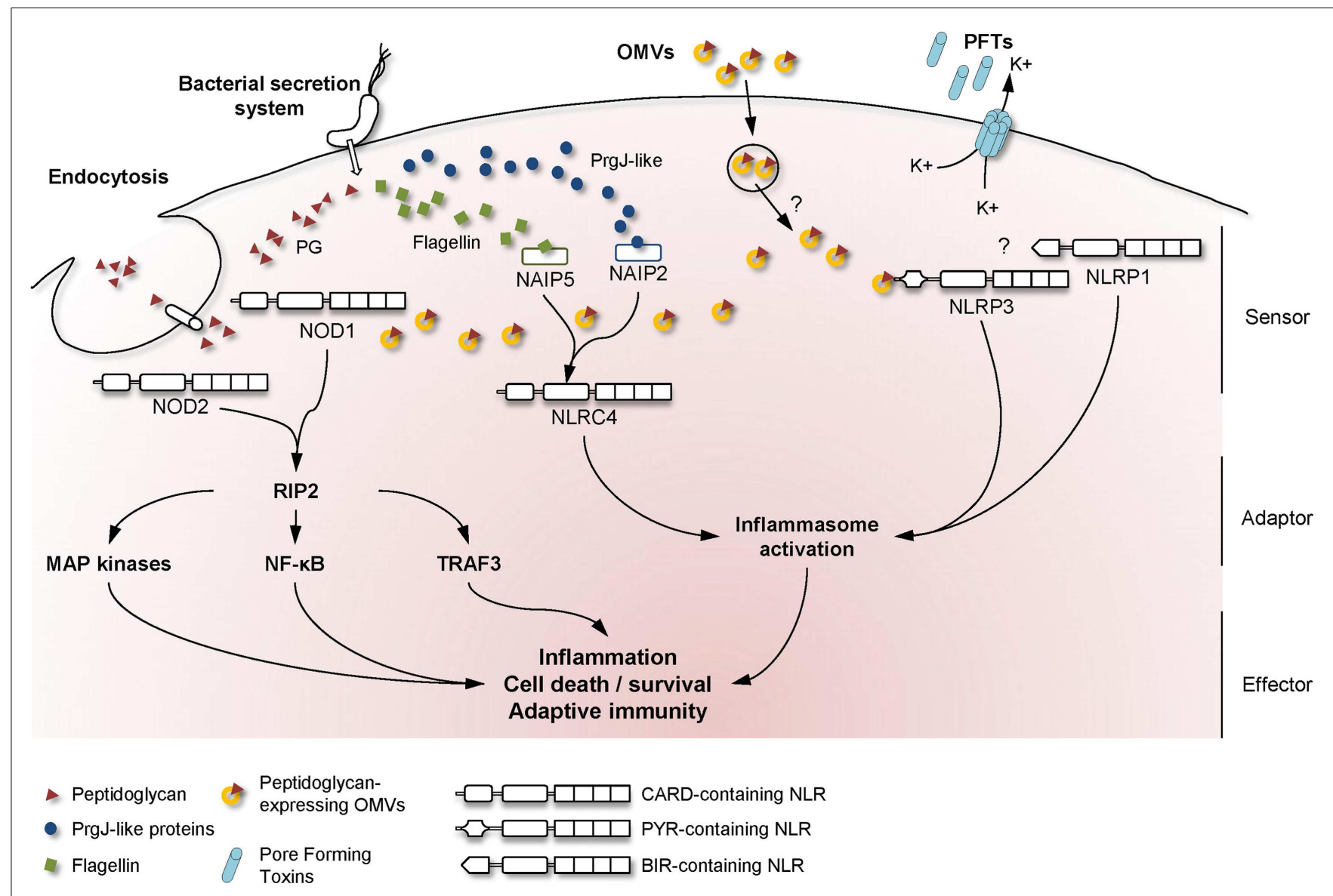

FIGURE 1 | Mechanisms used by bacteria to activate NLR signaling in host cells. A schematic overview of the major NLR signaling pathways activated during bacterial infection, showing the mechanisms whereby extracellular MAMPs are sensed by intracellular NLRs. Upon detection of the appropriate signal, NLRs are believed to oligomerize and recruit adaptor proteins to transduce the signal to downstream effector proteins.
(6). Specifically, the authors showed that H. pylori strains with a functional T4SS were able to deliver degradation products of Gram-negative cell wall peptidoglycan, identified as potent activators of NOD1 signaling (30), to epithelial cells (Table 1). The mechanism of how $H$. pylori peptidoglycan is delivered to cytosolic NOD1, however, is still unclear, even if it was reported that depletion of cholesterol-rich domains, or lipid rafts, interferes with peptidoglycan delivery into host cells (31). In any case, $H$. pylori T4SS-dependent induction of the NOD1 pathway was shown to result in the downstream activation of NF- $\kappa$ B and MAP kinases, most likely through the recruitment of the serine-threonine kinase adaptor molecule, RIP2 $(32,33)$. These findings are consistent with the general view that the NOD1 signaling pathway converges on the master transcriptional regulator, $N F-\kappa B$, leading to pro-inflammatory cytokine production [reviewed in Ref. (34)]. One group, however, suggested that NOD1 signaling is largely independent of NF-кB and MAPK activation (35). Instead, these workers presented data showing that the dominant response mediated by NOD1 activation involves the formation of a complex known as IFN-stimulated gene factor 3 (ISGF3) and production of CXCL10 and type I IFN by epithelial cells (35). The authors demonstrated that stimulation of AGS gastric epithelial cells with either a synthetic NOD1 agonist or live H. pylori bacteria alone induced increased CXCL10 production. Nevertheless, the potential link between NOD1 and type I IFN in epithelial cell responses, though interesting, awaits confirmation by other researchers.

Since the work on the role of NOD1 in H. pylori sensing, other bacterial pathogens have been identified as also being activators of this pathway, e.g., Pseudomonas aeruginosa and Campylobacter jejuni $(36,37)$. These bacteria have essentially extracellular lifestyles, although some data suggest that NOD1 activation in these infection models may be due to the presence of intracellular bacteria. However, even if invasive P. aeruginosa and C. jejuni have been shown to be present in defined intracellular structures, peptidoglycan delivery, and activation of cytoplasmic sensors, such as NOD1, must still require an efficient secretion system $(38,39)$. Furthermore, a recent study has shown that Salmonella typhimurium activation of NOD1 and NOD2, a related molecule that senses all forms of bacterial peptidoglycan, may be invasion-independent but requires an intact T3SS for the injection into the cytoplasm of the bacterial protein, SipA (10). This work, identifying a novel agonist of NOD1- and NOD2-signaling, suggests that these NLR family members may be activated through a distinct pathway from that induced by bacterial peptidoglycan. The same group suggested 
recently that NOD1 could sense other patterns of pathogenesis, such as modification of the actin cytoskeleton. According to this intriguing new model, a T3SS-secreted protein of S. typhimurium, SopE, activates the small Rho GTPases, which then triggers the NOD1 signaling pathway (40).

Another major NLR family member that is activated by extracellular pathogens through the action of bacterial secretion systems is the CARD-containing protein, NLRC4 (previously known as Ice Protease-Activating Factor, IPAF) (Table 1). The early paradigm for NLRC4 activation was that this NLR senses bacterial flagellin within the cytoplasmic compartment of cells. Specifically, it was shown that T3SS-dependent translocation of S. typhimurium and $P$. aeruginosa flagellin into the host cell triggered NLRC4 activation in macrophages (41-44). Interestingly, subsequent reports contradicted this hypothesis as both Shigella flexneri, an aflagellated bacterium, and P. aeruginosa were also able to activate NLRC4 inflammasome in a flagellin-independent, but T3SS-dependent mechanism, suggesting the existence of one or several other ligands $(45,46)$. These findings have since been confirmed in various bacterial species and the molecules responsible for NLRC4 activation have now been identified. Thus, it was shown that the basal body rod components of T3SSs (rod protein) are detected during infection with either S. typhimurium (PrgJ), Burkholderia pseudomallei (BsaK), Escherichia coli (EprJ and EscI), S. flexneri (MxiI), or $P$. aeruginosa (PscI) (47). Interestingly, all these proteins appear to share a sequence motif present in the carboxy terminal region that is conserved in the flagellar protein, FliC, and detected by NLRC4 (47). The mechanism of how NLRC4 is able to sense and respond to two distinct bacterial products, flagellin or PrgJ-like proteins, has thus been deciphered. Concomitant animal infection studies from two different groups showed that the specificity of the NLRC4 inflammasome is determined by different NAIP paralogs $(11,12)$. In these new models, both flagellin and rod protein are injected through the T3SS and are specifically recognized by NAIP5/6 or NAIP2 respectively, confirming previous studies showing a physical association between NLRC4 and NAIP5 (Figure 1) (11, 12, 48). Interestingly, humans possess only one Naip gene compared with the six Naip genomic loci in mice, and the specificity of human NAIP appears to be different to the murine NAIPs as it is unresponsive to intracellular delivery of flagellin or PrgJ-like rod proteins (12). Although it has been shown that a PrgJ homolog, from the bacterium Chromobacterium violaceum, is specifically recognized by human NAIP (12), further studies are required to determine the importance of human NAIP during infection with common bacterial pathogens.

T4SS and flagellin have also both been suggested to play roles in NLRC4 activation during Legionella replication within macrophages, since the presence of all three elements (i.e., flagellin, a functional T4SS and NLRC4) is required to activate caspase1 in these cells. Consistent with these findings, in vivo studies confirmed that clearance of Legionella pneumophila required the presence of both flagellin and NLRC4 (49).

Finally, bacterial secretion systems have recently been implicated in the activation of the NLR PYD-containing protein 12 (NLRP12) by the pathogen, Yersinia pestis (Table 1) (13). The nature of the NLRP12 ligand is still unknown, however, by using a $Y$. pestis strain which lacks the virulence plasmid necessary for the formation of a T3SS, the authors were able to show that this secretion system was required for inflammasome activation and IL-1 $\beta$ release in bone marrow-derived macrophages (BMDMs) (13). The precise mechanism by which the $Y$. pestis T3SS mediates NLRP12 inflammasome activation remains to be elucidated.

\section{OUTER MEMBRANE VESICLES}

In addition to bacterial secretion systems, in which individual proteins or macromolecules are secreted, bacteria have developed other mechanisms to transfer a wide variety of components within the host cells. The release of outer membrane vesicles (OMVs) is one such strategy developed by Gram-negative bacteria to secrete toxins, enzymes, DNA, adhesins, or other periplasmic constituents into the extracellular medium [reviewed in Ref. (50)]. It is also noteworthy that the commensal bacterium, Bacteroides fragilis, releases a capsular polysaccharide in its OMVs that has immunomodulatory effects and can prevent inflammation in an experimental colitis model (51). OMVs are released by virtually all Gram-negative bacteria, whereas the level of expression differs between bacterial species (50). More recent reports also suggest that Gram-positive bacteria can secrete membrane vesicles, however, these are less well studied than those of Gram-negative organisms $(52,53)$. OMVs can be released under different conditions in vitro and in vivo from free-living cells, biofilms, or by internalized bacteria (54-56).

The primary roles of OMVs are believed to be the delivery of toxins or bacterial components into host cells and the evasion of host immune responses (57). On the other hand, several studies have revealed that OMVs are able to induce inflammatory responses that may protect the host from infection. Indeed, OMVs contain different MAMPs, including LPS, flagellin, or DNA that could be recognized by TLR and NLR family members $(51,58$, 59). Traditionally, many studies in the literature have focused on OMV-associated LPS, however, it is now becoming apparent that peptidoglycan represents a major promoter of the inflammatory responses induced by OMVs. An initial clue to the potential role of OMV-associated peptidoglycan in innate immunity arose from the observation that $S$. flexneri culture supernatants, when microinjected into epithelial cells, induced the activation of the NF- $\mathrm{B}$ signaling pathway $(30,60)$. Indeed, it was shown that the OMVs normally present in such supernatants are able to enter nonphagocytic cells and deliver peptidoglycan directly to cytoplasmic NOD1, resulting in the up-regulation of NF- $\kappa \mathrm{B}$ and IL- 8 responses in cells (Figure 1) (7). This OMV-dependent mechanism of NOD1 activation was demonstrated for three extracellular pathogens: H. pylori, P. aeruginosa, and Neisseria gonorrhoeae (Table 1) (7). Moreover, it was shown that Nod1-deficient mice intragastrically fed with $H$. pylori OMVs failed to mount local $\mathrm{Cxcl} 2$ and systemic antibody responses, when compared with their wild-type littermates (7).

Subsequent studies reported that Vibrio cholerae strains, which also produce large amounts of OMVs, can promote immune responses in the host via a NOD1- and NOD2-dependent mechanism $(8,9)$. OMVs isolated from Moraxella catarrhalis have also been shown to induce IL- 8 production through TLR2-initiated NF- $\mathrm{B}$ activation, but a role for NOD1 could not been excluded, as cellular responses to whole bacteria involved both TLR2 and 
NOD1 $(61,62)$. Pro-inflammatory responses to OMVs were also observed for several other bacteria [reviewed in Ref. (50)], however, the role of peptidoglycan in these responses was not assessed.

Besides peptidoglycan, OMVs contain other molecules able to activate the innate immune system. For example, $N$. gonorrhoeae OMVs contain lipooligosaccharide (LOS) which has been shown to activate NLRP3-induced IL- $1 \beta$ secretion and pyronecrosis in monocytes and macrophages (Figure 1) (14, 15). This LOSmediated activation of the NLRP3 inflammasome is believed to be triggered by the release of cathepsin B (15).

Mechanistic data on OMV uptake are scarce, but recent findings suggest that disruption of lipid rafts by treatment with Fumonisin $\mathrm{B}_{1}$, an inhibitor of sphingomyelin incorporation into lipid rafts, or methyl- $\beta$-cyclodextrin, a cholesterol-depleting agent, abrogates both internalization and NOD1-dependent immunostimulatory capacity of OMVs (7). The mechanism and intracellular compartment(s) involved in NOD1 sensing of OMV-associated peptidoglycan, however, have yet to be determined.

The findings concerning the role of peptidoglycan delivery by OMVs provide a new mechanism to understand how extracellular bacteria, which are unable to invade cells or to inject components through a secretion system, may be able to initiate innate immune signaling in non-phagocytic cells, such as epithelial cells.

\section{PORE-FORMING TOXINS}

In addition to OMVs, bacteria may secrete toxins to alter host cell integrity distant to the original point of invasion. Among these proteins are the pore-forming toxins (PFTs), which are produced by a wide range of pathogens. PFTs are secreted in a soluble form and are subsequently multimerized into a transmembrane channel that perforates the plasma membrane of host cells. Pore formation may be an entry door for bacterial molecules to penetrate into host cells or lead to cellular ion imbalance (63). Efforts during the last decade have been focused on determining how cells are able to mount a response against pore formation, thereby contrasting with the existing paradigm, which suggested that cells possessed no defenses against these toxins and that the only outcome was cell death $(63,64)$. Numerous studies, indeed, found that stimulation of immune cells with different PFTs activates pro-inflammatory signaling or vacuolation in response to treatment [(65); and reviewed in Ref. (64)]. It is also noteworthy that the concentrations of PFTs during in vivo infection could be sublytic, thus allowing cells to mount an antibacterial response (66), capable of controlling the infection.

Recent intensive studies on PFTs and cellular responses have revealed a major role for NLRP3 in the sensing of pore formation. Mariathasan et al. demonstrated a role for listeriolysin $\mathrm{O}$ from Listeria monocytogenes, as well as for an unknown Staphylococcus aureus toxin, in inflammasome activation and IL-1 $\beta$ production (Table 1). Furthermore, this study speculated that the observed effects were dependent on intracellular potassium levels (Figure 1) (17). Concerning $S$. aureus, recent studies showed that caspase-1 activation requires the presence of all three of its $\alpha-, \beta$-, and $\gamma$ hemolysins and the release of bacterial lipoproteins $(19,24)$. In addition, a small percentage of $S$. aureus isolates also produce another toxin, named Panton-Valentine leukocidin (PVL), which is able to trigger NLRP3 inflammasome activation (25). These results were confirmed using aerolysin from Aeromonas hydrophila which was shown to mediate the efflux of intracellular potassium ions and activation of caspase-1 through the assembly of NLRC4 and NLRP3 inflammasomes (16). Subsequent studies suggested that aerolysin from either $A$. veronii or A. hydrophila activates only the NLRP3 inflammasome, through potassium efflux, whereas NLRC4 activation was T3SS-dependent but potassiumindependent $(21,22)$. During the last decade, a large number of bacterial PFTs have been shown to be able to activate NLRP3 via the same molecular mechanism of potassium efflux. These PFTs include the adenylate cyclase toxin (CyaA) from Bordetella pertussis (20), pneumolysin from Streptococcus pneumoniae (23), HlyA hemolysin and MARTX from Vibrio vulnificus and V. cholerae (23), streptolysin O from Streptococcus pyogenes (18). Even if the molecular mechanism is unclear, NLRP3 inflammasome assembly occurs spontaneously at low potassium concentrations and is prevented at higher concentrations, thus confirming its role in the detection of DAMPs (67). In a recent study, potassium efflux was shown to be the minimal membrane permeabilization event triggering NLRP3 inflammasome activation by PFTs and particulate matter (68).

In contrast to our understanding of NLRP3 biology, far less is known about activation of the NLRP1 inflammasome and its activation by PFTs. The human Nlrp1 gene has three murine paralogs, which encode proteins lacking the N-terminal PYD sequence found in human NLRP1 (69). Sensitivity of mice to the effects of anthrax lethal toxin from Bacillus anthracis has been correlated with a polymorphism in the Nalplb gene, encoding Nlrp1 (26). Due to the absence of a PYD domain in the mouse sequence of Nlrp1, it is not clear whether caspase-1 recruitment requires ASC or dimerization with another NLRP. However, recent data suggest that upon stimulation with anthrax lethal toxin, NLRP1 undergoes autoproteolysis to form an inflammasome (70). Interestingly, inflammasome formation and caspase-1 recruitment are inhibited by high levels of potassium (71). Hsu et al. demonstrated a role for NOD2 in lethal toxin-induced IL- $1 \beta$ production and suggested the formation of a complex between NLRP1 and NOD2 (72). This association has since been confirmed by other authors (73). Interestingly, NOD2-recognition of S. aureus is facilitated by the presence of its hemolysin, probably by promoting cytoplasmic access of NOD2 ligand (74).

Synergistic responses from the activation of multiple NLR pathways have been observed following co-stimulation with two different pathogens. Indeed, it was shown that Haemophilus influenzae peptidoglycan enters epithelial cells more efficiently in the presence of S. pneumoniae pneumolysin, suggesting the ability of intracellular NLRs to sense extracellular bacteria that do not encode secretion systems or express OMVs or PFTs (75). One hypothesis from the authors is that host organisms have evolved to detect a combination of pathogens in order to mount optimal responses in ways that are different to the responses induced by a single infection. It is now recognized that co-infection plays a previously unappreciated yet important role in the development of mucosal immunity and disease progression (76).

In conclusion, increasing numbers of studies suggest that osmotic changes induced by pore formation may be sensed by 
intracellular NLRs as an early warning system (68). Furthermore, these signals can cooperate with other signaling pathways, thus leading to the generation of antibacterial responses before the concentration of PFTs reaches a lytic concentration.

\section{ENDOCYTOSIS}

Asides from the active processes described above, intracellular NLRs may be activated by passive mechanisms. One such mechanism involves cellular entry by the peptidoglycan fragments that are released during bacterial growth or are degraded by host enzymes. Bacteria express peptidoglycan-degrading enzymes, necessary for maintaining functional growth, division, and development [reviewed in Ref. $(77,78)$ and $(79)]$. In addition to their role in shaping bacterial membranes, these enzymes are responsible for the release of free peptidoglycan fragments in the extracellular compartment. It is thus possible that these fragments interact with surrounding organisms, mediating pathogenic effects on host cells, as mutations in peptidoglycan-recycling proteins result in decreased pathogenesis. Conversely, released peptidoglycan fragments can also play a role in symbiotic relationships, such as is the case with Vibrio fischeri, which induces developmental changes in its squid host [reviewed in Ref. (77)]. Moreover, peptidoglycan can have effects on host cells distant to the point of its release. For example, peptidoglycan released in the gut was shown to circulate and play a major role in the priming of neutrophils in the bone marrow (80). Interestingly, a study by Hasegawa et al. characterizing NOD1- and NOD2-stimulatory activities in different bacterial preparations, showed that the highest levels of NOD1-stimulatory activity were found predominantly in culture supernatants, whereas NOD2 activity was associated with extracts from whole bacterial cells (81). This study further underscores the likely important role of released peptidoglycan during infection with extracellular bacteria.

On the other hand, host cells have also developed some mechanisms to degrade bacterial peptidoglycan in order to kill invading pathogens and provide ligands to host receptors [reviewed in Ref. (82)]. Enzymes such as lysozyme or peptidoglycan recognition protein family members generate fragments small enough to be sensed by NOD1 and NOD2 $(82,83)$.

In the context of extracellular pathogens, we can then wonder how these peptidoglycan fragments are processed to be presented to intracellular innate immune sensors. It is now established that different internalization mechanisms can be used by the host cell and these are probably cell-type dependent. In the case of epithelial cells, it has been reported that NOD1 and NOD2 ligands are likely to be internalized by clathrin-mediated endocytosis $(84,85)$. In immune cells, it is more likely that internalization occurs through phagocytosis. Interestingly, it has been observed that Nod1- or Nod2-deficient mice have decreased phagocytic abilities $(86,87)$.

Once the fragments have been internalized in vesicles by clathrin-mediated endocytosis or phagocytosis, they have to be delivered across membranes and be presented to the cytosolic molecules, NOD1 and NOD2. This mechanism implies the presence of specific transporters, with the transporter family SLC15 having been proposed to play a role. This transporter family comprises membrane proteins controlling the cellular uptake of di/tripeptides and peptide-like drugs [reviewed in Ref. (88)]. Roles for SLC15A4 (PHT1) and SLC15A2 (PepT2) have indeed been identified for the delivery of NOD1-ligands (Figure 1) (84, 89, 90). Another member of this family, SLC15A1 (PepT1), is believed to play a role in NOD2 ligand transport $(85,91)$. Nevertheless, the specificity of each of these transporters is still unclear, as both the minimal motif recognized by NOD1, iE-DAP $(\gamma$-D-GlumDAP), and the NOD2 agonist, MDP (MurNAc-L-Ala-D-isoGln, also known as muramyl dipeptide) may be delivered through SLC15A2 $(89,92)$. Interestingly, there are higher expression levels of SLC15A1, SLC15A2, and SLC15A4 in the small intestine, with lower bacterial loads of $10^{3}$ organisms per gram, than in the colon, where microbial densities reach $10^{12}$ organisms per gram. This may suggest a role for such transporter proteins in MAMP uptake [reviewed in Ref. (93), and (1)].

\section{CONTROL OF ADAPTIVE IMMUNITY}

Activation of NLRs has been shown to prime T and B cells, suggesting the contribution of these innate immune molecules in the development of adaptive immune responses. Interestingly, many of the known NLRs activators (e.g., MDP, flagellin, alum) play roles as adjuvants during vaccination, suggesting a role for these molecules in tailoring the adaptive immune response [reviewed in Ref. (94)].

The most striking example is the role played by NOD2 in the mediation of the adjuvant effect of complete Freund's adjuvant, first described in 1937 (95). The adjuvant activity of this compound, which is composed of paraffin oil and Mycobacterium tuberculosis extract, is believed to be attributed to its ability to prolong antigen release, to promote the recruitment of immune cells and antigen presentation by inducing expression of cytokines and chemokines [reviewed in Ref. (96)]. The minimal component of complete Freund's adjuvant was subsequently identified to be MDP, as this molecule provided the same level of adjuvant activity as whole killed M. tuberculosis (97). The mechanism responsible for the activity of Freund's adjuvant was determined less than 10 years ago by Kobayashi et al. who showed that NOD2 was required for the development of protective immunity mediated by the adjuvant effects of MDP (98). During immunization assays in Nod $2^{-1-}$ animals, a severe deficiency was observed in the production of antigen-specific immunoglobulins, specifically in those of the IgG1 subclass, suggesting that NOD2 is able to activate the adaptive immune system and promote the production of antibodies to T cell-dependent antigens (98). These results were confirmed subsequently, when it was shown that MDP injection in mice triggered Th2 polarized responses in a NOD2-dependent manner (99). Specifically, it was shown that Nod2-deficient mice displayed impaired chemokine and Th2 responses with low numbers of splenic IL-4- and IL-5-producing T cells, as well as the loss of antigen-specific T and B cell responses (99). Interestingly, NOD2 can also cooperate with TLRs to generate Th1-polarized responses to co-stimulation with MDP and TLR2 or TLR4 ligands, suggesting the importance of complementary effects between TLRs and NLRs in the balance of immune effector responses (99). In addition to the recognition of MDP by NOD2, dual recognition of a mycobacterial glycolipid, also known as cord factor, and peptidoglycan is essential for Th17-differentiation in an inflammasome-dependent 
manner (100). It was shown that recognition of both the mycobacterial cord factor by the CARD9-dependent C-type lectin receptor mincle and peptidoglycan, via a NOD1- and NOD2-independent mechanism, induces inflammasome activation and IL- $1 \beta$ secretion and thus drives skewed Th17 responses.

NOD1 stimulation has also been shown to be sufficient to drive antigen-specific immunity with a predominant Th2 polarization profile and to play a role in the onset of Th1, Th2, and Th17 immune pathways in conjunction with TLR stimulation (101). Thus, depending on the presence of different MAMPS and the costimulation of TLRs, NOD receptors can initiate different arms of the adaptive response. Although data are still scarce concerning the role of NOD1 and NOD2 in the onset of adaptive immunity during microbial infection, $H$. pylori-infected Nod1-deficient mice exhibited reduced Th1 immune responses compared with their WT littermates (101). Similar results were obtained in M. tuberculosis or S. pneumoniae-infected Nod2-deficient mice, with lower titers of pathogen-specific serum IgG and diminished antigenspecific T cell responses $(102,103)$. Consistent with these data, Citrobacter and Salmonella infections triggered Th17 responses that were dependent on NOD1 and NOD2 (104).

Injection of bone marrow reconstituted mice with NOD1 or NOD2 agonists and ovalbumin allowed the group of Philpott and collaborators to determine the importance of stromal factors, versus hematopoietic cells, in the initiation of Th2 immune responses $(101,105)$. In addition, that group showed that the capacity of NOD1 ligand to cooperate with TLR agonists was completely abolished in Nod1-deficient bone marrow-derived dendritic cells (BMDCs) (101). Similarly, Nod2-deficiency in BMDCs abolished pro-inflammatory cytokine production upon stimulation with MDP alone, whereas synergy between MDP and TLR ligands was lost in Nod2-deficient BMDMs (98). Additionally, full responses required sensing within the hematopoietic compartment, with a major role for dendritic cells, consistent with the well-established role of dendritic cells in the onset of adaptive immunity $(105,106)$. Furthermore, co-stimulation with NOD1 or NOD2 agonists in combination with TLR agonist induced a synergistic production of Th1-associated cytokines IFN- $\gamma$ and IL-12 (107).

In contrast to the now well-defined role of NOD proteins in tailoring adaptive immune responses, the role of the NOD $1 / 2$ adaptor protein, RIP2, is less well-defined. Several early works in in vivo or in vitro RIP2-deficient models demonstrated impairment in the development of anti-infectious responses, NF-кB signaling, or $\mathrm{T}$ cell proliferation and differentiation (108-110). On the other hand, more recent papers, all of them using the same mouse model but different to those used previously, claimed an absence of effect of RIP2 in T cell proliferation and T helper differentiation (111, 112). A comparison of the different RIP2-knockout mouse lines may help to resolve these differences.

Recent studies have shown that non-hematopoietic cells can also be of importance during the development of adaptive immune responses. Indeed, Watanabe et al. proposed that activation of NOD1 and NOD2 in gastrointestinal epithelial cell lines induces production of cytokines associated with a Th1 response (35). They also proposed that NOD1 signaling, through ISGF3 activation and type I IFN responses, may lead to Th1 differentiation and Th1-dependent inflammation (35).

Concerning the other NLR family members, further studies will be needed to help to understand their roles in adaptive immunity. It has been shown using the Listeria infection mouse model that strains that activated the inflammasome generated significantly less protective immunity, a phenotype that correlated with decreased induction of antigen-specific T cells (113). It is noteworthy that IL- 1 family cytokines, including IL- $1 \beta$ and IL- 18 , have adjuvant properties, as they can induce antigen-specific immune responses against infection (114). For example, CyaA, a poreforming toxin from $B$. pertussis, activates the NLRP3 inflammasome and induces IL-1 $\beta$ expression, thereby playing a critical role in promoting antigen-specific Th17 cells and in generating protective immunity against $B$. pertussis infection (20). Interestingly, a recent report suggested that IL- $1 \beta$ production in trophoblasts after Chlamydia trachomatis infection may also be mediated by NOD1, but the signaling pathway involved remains unclear (115). In addition, IL-1 $\beta$ may be secreted after non-canonical inflammasome activation, where an intracellular lipid A moiety of LPS has been showed to play major roles in the induction of TLR4independent inflammatory responses (116). Although the receptor has as yet to be characterized, these results suggest a new mechanism of intracellular sensing in the mounting of innate immune responses against microbial infection.

\section{CONCLUDING REMARIKS}

As discussed above, various NLR family members have evolved to detect infection and mount effective immune responses mediated by both innate and adaptive arms of the immune system. Asides from these NLR family members, it is possible that other family members could play roles during infection with extracellular bacteria. Indeed, NLRP6-deficiency in mice was shown to result in increased inflammation, to alter the colonic microbial ecology and was associated with susceptibility to colorectal tumorigenesis $(117,118)$. More recently, NLRP6 has been shown to inhibit NF- $\kappa$ B translocation and MAPK activation, with NLRP6 activation leading to increased susceptibility to both intracellular and extracellular bacteria (119). Thus, a second subclass of NLR family members, such as NLRP6 or NLRC5, may act as molecular switches to dampen host responses induced by extracellular bacteria. For example, NLRC5 has been suggested to interact with NF- $\mathrm{B}$ regulators, IKK $\alpha$ and IKK $\beta$, and to block their phosphorylation so as to modulate inflammatory signaling to bacterial pathogens (120). Discordant results were, however, obtained in different studies (121-123), suggesting that further investigations are required to fully elucidate the role(s) of NLRC5 in host responses to microbial pathogens. Besides the NLR family members described in this review, other intracellular molecules, such as certain TLRs (i.e., TLR3, TLR9) or Absent In Melanoma 2 (AIM2), are able to detect nucleic acids from extracellular bacteria, allowing a wide range of MAMPs to be sensed.

The different examples of infection sensing described above highlight the existence of dual systems of recognition for MAMPs from extracellular bacteria. First, conserved molecular patterns in bacteria may be recognized by extracellular receptors. For 
instance, sensing of bacterial lipoproteins by TLR2, LPS by TLR 4 or flagellin by TLR5 have been relatively well described. Activation of these extracellular receptors leads to a transcriptional inflammatory response with production of type I IFNs or proinflammatory cytokines, such as TNF- $\alpha$ or IL-12. However, particular cytokines, including IL- $1 \beta$ or IL- 18 , require an additional post-transcriptional step to be fully functional. A growing amount of evidence suggests that the signaling involved in this posttranscriptional response is due to activation of inflammasome complexes, after sensing of microbes or danger signals by intracellular molecules, including the NLRs. However, some intracellular sensors of extracellular bacteria, such as NOD1 and NOD2, do not induce inflammasome formation and are generally thought to activate NF- $\mathrm{KB}$ signaling instead. Nevertheless, we can reasonably hypothesize that host cells are able to distinguish between the signals originating from extracellular and intracellular pathogens, through the intensity, kinetics, or cell-specific nature of the signal.

This dual recognition of the pathogen itself, or of the consequences of the infection, may be of importance to finely tune inflammatory responses in line with the threat. One hypothesis is that non-pathogenic bacteria may be recognized by extracellular receptors only, whereas pathogenic extracellular or invasive bacteria will be sensed by both families of receptors, leading to more intense responses, suggesting that synergy between TLRs and NLRs may be required for optimal responses. As evoked in this review, it was found that NLR family members may synergize with TLRdependent cytokine expression (124). An interesting example of this possible dual recognition would be the gut, where there is exposure to more than 500 species of commensal microorganisms. It has been shown that TLR agonists induced tolerance to subsequent stimulation with the same agonist (125). This process could thus play a role in the induction of tolerance to commensal bacteria, whereas pathogenic microorganisms could then be sensed by NLR family members.

\section{REFERENCES}

1. Sommer F, Backhed F. The gut microbiota-masters of host development and physiology. Nat Rev Microbiol (2013) 11:227-38. doi: 10.1038/nrmicro2974

2. Rakoff-Nahoum S, Paglino J, Eslami-Varzaneh F, Edberg S, Medzhitov R. Recognition of commensal microflora by toll-like receptors is required for intestinal homeostasis. Cell (2004) 118:229-41. doi:10.1016/j.cell.2004.07.002

3. Ting JP, Lovering RC, Alnemri ES, Bertin J, Boss JM, Davis $\mathrm{BK}$, et al. The NLR gene family: a standard nomenclature. Immunity (2008) 28:285-7. doi:10.1016/ j.immuni.2008.02.005

4. Kufer TA, Sansonetti PJ. NLR functions beyond pathogen recognition. Nat Immunol (2011) 12:121-8. doi:10.1038/ni. 1985

It is possible that, depending on the cell type, host cells may distinguish between the signal originating from TLRs and NLRs. Gut immunology provides a good example of how this might work. Indeed, the intestinal epithelium is composed of different layers allowing discrimination between commensal and pathogenic bacteria. The outermost of these layers, comprising the mucus, is a barrier surrounding intestinal epithelial cells. Some areas of the intestinal epithelium, such as the Peyer's patches, are devoid of mucus and serve as inductive sites for the mucosal immune system. In addition, dendritic cells can extend pseudopodes through the mucus and reach the lumen [reviewed in Ref. (126)]. This multi-layer system could allow the host to distinguish between a commensal, which should not progress through the mucosa, and a pathogen, which could disseminate beyond this layer and/or present bacterial components to the epithelium (127). Hence, the ability of the host to distinguish between commensals and pathogens and to mount efficient immune responses could be dependent on how and where the MAMPs are sensed (128).

As discussed in this review, activation of NLR-dependent signaling pathways by extracellular bacteria induces the direct production of pro-inflammatory molecules and also tailors and drives adaptive immunity, suggesting that NLR family members are multifaceted proteins. A comprehensive understanding of the functions of NLRs will help decipher their roles in shaping both innate and adaptive immunity during infection with extracellular pathogens.

\section{ACKNOWLEDGMENTS}

This work was supported by the Victorian Government's Operational Infrastructure Support Program to MIMR and grant to Richard Louis Ferrero from the National Health and Medical Research Council of Australia (APP1030243). Richard Louis Ferrero is supported by a Senior Research Fellowship, awarded by the National Health and Medical Research Council.

receptor activation by outer membrane vesicles from Vibrio cholerae non-O1 non-O139 strains is modulated by the quorum-sensing regulator HapR. Infect Immun (2011) 79:1418-27. doi:10.1128/ IAI.00754- 10

9. Chatterjee D, Chaudhuri K. Vibrio cholerae $\mathrm{O} 395$ outer membrane vesicles modulate intestinal epithelial cells in a NOD1 protein-dependent manner and induce dendritic cell-mediated Th2/Th17 cell responses. J Biol Chem (2013) 288:4299-309. doi: 10.1074/jbc.M112.408302

10. Keestra AM, Winter MG, KleinDouwel D, Xavier MN, Winter SE, Kim A, et al. A Salmonella virulence factor activates the NOD1/NOD2 signaling pathway. MBio (2011) 2(6):e00266-11 . doi: 10.1128/mBio.00266-11

11. Kofoed EM, Vance RE. Innate immune recognition of bacterial ligands by NAIPs determines inflammasome specificity. Nature (2011) 477:592-5. doi:10.1038/ nature 10394

12. Zhao Y, Yang J, Shi J, Gong YN, Lu $\mathrm{Q}, \mathrm{Xu} \mathrm{H}$, et al. The NLRC4 inflammasome receptors for bacterial flagellin and type III secretion apparatus. Nature (2011) 477:596-600. doi:10.1038/nature10510

13. Vladimer GI, Weng D, Paquette SW, Vanaja SK, Rathinam VA, Aune $\mathrm{MH}$, et al. The NLRP12 inflammasome recognizes Yersinia pestis. Immunity (2012) 37:96-107. doi: 10.1016/j.immuni.2012.07.006

14. Fisseha $M$, Chen P, Brandt B, Kijek T, Moran E, Zollinger W. Characterization of native outer membrane vesicles from lpxL mutant strains of Neisseria meningitidis for use in parenteral vaccination. Infect Immun (2005) 73:4070-80. doi:10.1128/IAI.73.7. 4070-4080.2005 
15. Duncan JA, Gao X, Huang MT, O'Connor BP, Thomas CE, Willingham SB, et al. Neisseria gonorrhoeae activates the proteinase cathepsin B to mediate the signaling activities of the NLRP3 and ASC-containing inflammasome. $J$ Immunol (2009) 182:6460-9. doi: 10.4049/jimmunol.0802696

16. Gurcel L, Abrami L, Girardin S, Tschopp J, Van Der Goot FG. Caspase-1 activation of lipid metabolic pathways in response to bacterial pore-forming toxins promotes cell survival. Cell (2006) 126:1135-45. doi:10.1016/ j.cell.2006.07.033

17. Mariathasan S, Weiss DS, Newton K, McBride J, O'Rourke K, Roose-Girma $\mathrm{M}$, et al. Cryopyrin activates the inflammasome in response to toxins and ATP. Nature (2006) 440:228-32. doi:10.1038/ nature 04515

18. Harder J, Franchi L, MunozPlanillo R, Park JH, Reimer T, Nunez G. Activation of the Nlrp3 inflammasome by Streptococcus pyogenes requires streptolysin $\mathrm{O}$ and NF-kappa B activation but proceeds independently of TLR signaling and $\mathrm{P} 2 \mathrm{X} 7$ receptor. $J$ Immunol (2009) 183:5823-9. doi: 10.4049/jimmunol.0900444

19. Munoz-Planillo R, Franchi L, Miller LS, Nunez G. A critical role for hemolysins and bacterial lipoproteins in Staphylococcus aureus-induced activation of the Nlrp3 inflammasome. J Immunol (2009) 183:3942-8. doi:10.4049/ jimmunol.0900729

20. Dunne A, Ross PJ, Pospisilova E, Masin J, Meaney A, Sutton $\mathrm{CE}$, et al. Inflammasome activation by adenylate cyclase toxin directs Th17 responses and protection against Bordetella pertussis. J Immunol (2010) 185:1711-9. doi:10.4049/jimmunol.1000105

21. McCoy AJ, Koizumi Y, Higa N, Suzuki T. Differential regulation of caspase-1 activation via NLRP3/NLRC4 inflammasomes mediated by aerolysin and type III secretion system during Aeromonas veronii infection. J Immunol (2010) 185:7077-84. doi:10.4049/jimmunol.1002165

22. McCoy AJ, Koizumi Y, Toma C, Higa N, Dixit V, Taniguchi S, et al. Cytotoxins of the human pathogen Aeromonas hydrophila trigger, via the NLRP3 inflammasome, caspase-1 activation in macrophages. Eur J Immunol (2010) 40:2797-803. doi:10.1002/ eji. 201040490
23. McNeela EA, Burke A, Neill DR, Baxter C, Fernandes VE, Ferreira $\mathrm{D}$, et al. Pneumolysin activates the NLRP3 inflammasome and promotes proinflammatory cytokines independently of TLR4. PLoS Pathog (2010) 6:e1001191. doi:10.1371/journal.ppat.1001191

24. Kebaier C, Chamberland RR, Allen IC, Gao X, Broglie PM, Hall JD, et al. Staphylococcus aureus alphahemolysin mediates virulence in a murine model of severe pneumonia through activation of the NLRP3 inflammasome. J Infect Dis (2012) 205:807-17. doi:10.1093/ infdis/jir846

25. Holzinger D, Gieldon L, Mysore V, Nippe N, Taxman DJ, Duncan JA, et al. Staphylococcus aureus Panton-Valentine leukocidin induces an inflammatory response in human phagocytes via the NLRP3 inflammasome. $J$ Leukoc Biol (2012) 92:1069-81. doi:10.1189/jlb.0112014

26. Boyden ED, Dietrich WF. Nalp1b controls mouse macrophage susceptibility to anthrax lethal toxin. Nat Genet (2006) 38:240-4. doi:10. 1038/ng1724

27. Cornelis GR. The type III secretion injectisome. Nat Rev Microbiol (2006) 4:811-25. doi:10.1038/ nrmicro1526

28. Tseng TT, Tyler BM, Setubal JC. Protein secretion systems in bacterial-host associations, and their description in the Gene Ontology. BMC Microbiol (2009) 9(Suppl 1):S2. doi:10.1186/14712180-9-S1-S2

29. Voth DE, Broederdorf LJ, Graham JG. Bacterial Type IV secretion systems: versatile virulence machines. Future Microbiol (2012) 7:241-57. doi:10.2217/fmb.11.150

30. Girardin SE, Boneca IG, Carneiro LA, Antignac A, Jehanno M, Viala $J$, et al. Nod 1 detects a unique muropeptide from gram-negative bacterial peptidoglycan. Science (2003) 300:1584-7. doi:10.1126/ science. 1084677

31. Hutton ML, Kaparakis-Liaskos M, Turner L, Cardona A, Kwok T, Ferrero RL. Helicobacter pylori exploits cholesterolrich microdomains for induction of NF-kappaB-dependent responses and peptidoglycan delivery in epithelial cells. Infect Immun (2010) 78:4523-31. doi:10.1128/IAI.00439-10

32. Allison CC, Kufer TA, Kremmer E, Kaparakis M, Ferrero RL. Helicobacter pylori induces MAPK phosphorylation and
AP-1 activation via a NOD1dependent mechanism. J Immunol (2009) 183:8099-109. doi:10.4049/jimmunol.0900664

33. Allison CC, Ferrand J, McLeod L, Hassan M, Kaparakis-Liaskos M, Grubman A, et al. Nucleotide oligomerization domain 1 enhances IFN-gamma signaling in gastric epithelial cells during Helicobacter pylori infection and exacerbates disease severity. J Immunol (2013) 190:3706-15. doi:10.4049/jimmunol.1200591

34. Correa RG, Milutinovic S, Reed JC. Roles of NOD1 (NLRC1) and NOD2 (NLRC2) in innate immunity and inflammatory diseases. Biosci Rep (2012) 32:597-608. doi: 10.1042/BSR20120055

35. Watanabe T, Asano N, FichtnerFeigl S, Gorelick PL, Tsuji Y, Matsumoto Y, et al. NOD1 contributes to mouse host defense against Helicobacter pylori via induction of type I IFN and activation of the ISGF3 signaling pathway. J Clin Invest (2010) 120:1645-62. doi:10. 1172/JCI39481

36. Travassos LH, Carneiro LA, Girardin SE, Boneca IG, Lemos R, Bozza MT, et al. Nodl participates in the innate immune response to Pseudomonas aeruginosa. J Biol Chem (2005) 280:36714-8. doi:10.1074/jbc.M501649200

37. Zilbauer M, Dorrell N, Elmi A, Lindley KJ, Schuller S, Jones HE, et al. A major role for intestinal epithelial nucleotide oligomerization domain 1 (NOD1) in eliciting host bactericidal immune responses to Campylobacter jejuni. Cell Microbiol (2007) 9:2404-16. doi:10.1111/j.1462-5822.2007. 01008.x

38. Angus AA, Lee AA, Augustin DK, Lee EJ, Evans DJ, Fleiszig SM. Pseudomonas aeruginosa induces membrane blebs in epithelial cells, which are utilized as a niche for intracellular replication and motility. Infect Immun (2008) 76:1992-2001. doi:10.1128/IAI.01221-07

39. Bouwman LI, Niewold P, Van Putten JP. Basolateral invasion and trafficking of Campylobacter jejuni in polarized epithelial cells. PLoS ONE (2013) 8:e54759. doi:10. 1371/journal.pone.0054759

40. Keestra AM, Winter MG, Auburger JJ, Frassle SP, Xavier MN, Winter $\mathrm{SE}$, et al. Manipulation of small Rho GTPases is a pathogeninduced process detected by NOD1. Nature (2013) 496:233-7. doi:10.1038/nature12025
41. Franchi L, Amer A, Body-Malapel M, Kanneganti TD, Ozoren N, Jagirdar R, et al. Cytosolic flagellin requires Ipaf for activation of caspase- 1 and interleukin 1beta in salmonella-infected macrophages. Nat Immunol (2006) 7:576-82. doi:10.1038/ni1346

42. Miao EA, Alpuche-Aranda CM, Dors M, Clark AE, Bader MW, Miller SI, et al. Cytoplasmic flagellin activates caspase-1 and secretion of interleukin lbeta via Ipaf. Nat Immunol (2006) 7:569-75. doi:10.1038/ni1344

43. Sun YH, Rolan HG, Tsolis RM. Injection of flagellin into the host cell cytosol by Salmonella enterica serotype Typhimurium. J Biol Chem (2007) 282:33897-901. doi: 10.1074/jbc.C700181200

44. Miao EA, Ernst RK, Dors M Mao DP, Aderem A. Pseudomonas aeruginosa activates caspase 1 through Ipaf. Proc Natl Acad Sci U S A (2008) 105:2562-7. doi:10. 1073/pnas.0712183105

45. Sutterwala FS, Mijares LA, Li L, Ogura Y, Kazmierczak BI, Flavell RA. Immune recognition of Pseudomonas aeruginosa mediated by the IPAF/NLRC4 inflammasome. J Exp Med (2007) 204:3235-45. doi:10.1084/jem.20071239

46. Suzuki T, Franchi L, Toma C, Ashida H, Ogawa M, Yoshikawa $\mathrm{Y}$, et al. Differential regulation of caspase-1 activation, pyroptosis, and autophagy via Ipaf and ASC in Shigella-infected macrophages. PLoS Pathog (2007) 3:e111. doi:10.1371/journal.ppat. 0030111

47. Miao EA, Mao DP, Yudkovsky N, Bonneau R, Lorang CG, Warren $\mathrm{SE}$, et al. Innate immune detection of the type III secretion apparatus through the NLRC4 inflammasome. Proc Natl Acad Sci U S A (2010) 107:3076-80. doi:10.1073/ pnas.0913087107

48. Zamboni DS, Kobayashi KS, Kohlsdorf T, Ogura Y, Long EM, Vance RE, et al. The Bircle cytosolic pattern-recognition receptor contributes to the detection and control of Legionella pneumophila infection. Nat Immunol (2006) 7:318-25. doi:10.1038/ni1305

49. Amer A, Franchi L, Kanneganti TD, Body-Malapel M, Ozoren $\mathrm{N}$, Brady G, et al. Regulation of Legionella phagosome maturation and infection through flagellin and host Ipaf. $J$ Biol Chem (2006) 281:35217-23. doi: 10.1074/jbc.M604933200 
50. Ellis TN, Kuehn MJ. Virulence and immunomodulatory roles of bacterial outer membrane vesicles. Microbiol $\mathrm{Mol}$ Biol Rev (2010) 74:81-94. doi:10.1128/MMBR.00031-09

51. Shen Y, Giardino Torchia ML, Lawson GW, Karp CL, Ashwell JD, Mazmanian SK. Outer membrane vesicles of a human commensal mediate immune regulation and disease protection. Cell Host Microbe (2012) 12:509-20. doi:10.1016/j.chom.2012.08.004

52. Lee EY, Choi DY, Kim DK, Kim JW, Park JO, Kim S, et al. Grampositive bacteria produce membrane vesicles: proteomics-based characterization of Staphylococcus aureus-derived membrane vesicles. Proteomics (2009) 9:5425-36. doi:10.1002/pmic.200900338

53. Rivera J, Cordero RJ, Nakouzi AS, Frases S, Nicola A, Casadevall A. Bacillus anthracis produces membrane-derived vesicles containing biologically active toxins. Proc Natl Acad Sci U S A (2010) 107:19002-7. doi:10.1073/ pnas. 1008843107

54. Garcia-del Portillo F, Stein MA, Finlay BB. Release of lipopolysaccharide from intracellular compartments containing Salmonella typhimurium to vesicles of the host epithelial cell. Infect Immun (1997) 65:24-34.

55. Schooling SR, Beveridge TJ. Membrane vesicles: an overlooked component of the matrices of biofilms. J Bacteriol (2006) 188:5945-57. doi:10.1128/JB.00257-06

56. Toyofuku M, Roschitzki B, Riedel K, Eberl L. Identification of proteins associated with the Pseudomonas aeruginosa biofilm extracellular matrix. J Proteome Res (2012) 11:4906-15. doi:10.1021/pr300395j

57. Tan TT, Morgelin M, Forsgren A, Riesbeck K. Haemophilus influenzae survival during complementmediated attacks is promoted by Moraxella catarrhalis outer membrane vesicles. J Infect Dis (2007) 195:1661-70. doi:10.1086/517611

58. Ellis TN, Leiman SA, Kuehn MJ. Naturally produced outer membrane vesicles from Pseudomonas aeruginosa elicit a potent innate immune response via combined sensing of both lipopolysaccharide and protein components. Infect Immun (2010) 78:3822-31. doi:10. 1128/IAI.00433-10

59. Sharpe SW, Kuehn MJ, Mason KM. Elicitation of epithelial cellderived immune effectors by outer membrane vesicles of nontypeable Haemophilus influenzae. Infect Immun (2011) 79:4361-9. doi:10.1128/IAI.05332-11

60. Philpott DJ, Yamaoka S, Israel A, Sansonetti PJ. Invasive Shigella flexneri activates NF-kappa B through a lipopolysaccharidedependent innate intracellular response and leads to IL-8 expression in epithelial cells. J Immunol (2000) 165:903-14.

61. Slevogt H, Seybold J, Tiwari KN, Hocke AC, Jonatat C, Dietel S, et al. Moraxella catarrhalis is internalized in respiratory epithelial cells by a trigger-like mechanism and initiates a TLR2- and partly NOD1-dependent inflammatory immune response. Cell Microbiol (2007) 9:694-707. doi:10.1111/j. 1462-5822.2006.00821.x

62. Schaar V, De Vries SP, Perez Vidakovics ML, Bootsma HJ, Larsson L, Hermans PW, et al. Multicomponent Moraxella catarrhalis outer membrane vesicles induce an inflammatory response and are internalized by human epithelial cells. Cell Microbiol (2011) 13:432-49. doi:10. 1111/j.1462-5822.2010.01546.x

63. Gonzalez MR, Bischofberger $M$, Pernot L, Van Der Goot FG, Freche B. Bacterial pore-forming toxins: the (w)hole story? Cell Mol Life Sci (2008) 65:493-507. doi:10.1007/ s00018-007-7434-y

64. Aroian R, van der Goot FG. Pore-forming toxins and cellular non-immune defenses (CNIDs). Curr Opin Microbiol (2007) 10:57-61. doi:10.1016/j.mib.2006. 12.008

65. Ratner AJ, Hippe KR, Aguilar JL, Bender $\mathrm{MH}$, Nelson AL, Weiser JN. Epithelial cells are sensitive detectors of bacterial poreforming toxins. $J$ Biol Chem (2006) 281:12994-8. doi:10.1074/ jbc.M511431200

66. Spreer A, Kerstan H, Bottcher T, Gerber J, Siemer A, Zysk G, et al. Reduced release of pneumolysin by Streptococcus pneumoniae in vitro and in vivo after treatment with nonbacteriolytic antibiotics in comparison to ceftriaxone. Antimicrob Agents Chemother (2003) 47:2649-54. doi:10.1128/ AAC.47.8.2649-2654.2003

67. Petrilli V, Papin S, Dostert C, Mayor A, Martinon F, Tschopp J. Activation of the NALP3 inflammasome is triggered by low intracellular potassium concentration. Cell Death Differ (2007) 14:1583-9. doi:10.1038/sj.cdd.4402195
68. Munoz-Planillo R, Kuffa P, Martinez-Colon G, Smith BL, Rajendiran TM, Nunez G. $\mathrm{K}^{+}$ efflux is the common trigger of NLRP3 inflammasome activation by bacterial toxins and particulate matter. Immunity (2013) 38:1142-53. doi:10.1016/j. immuni.2013.05.016

69. Moayeri M, Sastalla I, Leppla SH. Anthrax and the inflammasome. Microbes Infect (2012) 14:392-400. doi:10.1016/j.micinf.2011.12.005

70. Frew BC, Joag VR, Mogridge J. Proteolytic processing of Nlrplb is required for inflammasome activity. PLoS Pathog (2013) 8:e1002659. doi:10.1371/journal.ppat.1002659

71. Wickliffe KE, Leppla SH, Moayeri M. Anthrax lethal toxininduced inflammasome formation and caspase- 1 activation are late events dependent on ion fluxes and the proteasome. Cell Microbiol (2008) 10:332-43.

72. Hsu LC, Ali SR, McGillivray $\mathrm{S}$, Tseng $\mathrm{PH}$, Mariathasan $\mathrm{S}$, Humke EW, et al. A NOD2NALP1 complex mediates caspase1-dependent IL-1beta secretion in response to Bacillus anthracis infection and muramyl dipeptide. Proc Natl Acad Sci U S A (2008) 105:7803-8. doi:10.1073/ pnas.0802726105

73. Wagner RN, Proell M, Kufer TA, Schwarzenbacher R. Evaluation of Nod-like receptor (NLR) effector domain interactions. PLoS ONE (2009) 4:e4931. doi:10.1371/ journal.pone.0004931

74. Hruz P, Zinkernagel AS, Jenikova G, Botwin GJ, Hugot JP, Karin M, et al. NOD2 contributes to cutaneous defense against Staphylococcus aureus through alpha-toxindependent innate immune activation. Proc Natl Acad Sci U S A (2009) 106:12873-8. doi:10.1073/ pnas.0904958106

75. Ratner AJ, Aguilar JL, Shchepetov M, Lysenko ES, Weiser JN. Nod1 mediates cytoplasmic sensing of combinations of extracellular bacteria. Cell Microbiol (2007) 9:1343-51. doi:10.1111/j. 1462-5822.2006.00878.x

76. Lijek RS, Weiser JN. Co-infection subverts mucosal immunity in the upper respiratory tract. Curr Opin Immunol (2012) 24:417-23. doi: 10.1016/j.coi.2012.05.005

77. Cloud-Hansen KA, Peterson SB, Stabb EV, Goldman WE, McFallNgai MJ, Handelsman J. Breaching the great wall: peptidoglycan and microbial interactions. Nat
Rev Microbiol (2006) 4:710-6. doi: 10.1038/nrmicro1486

78. Park JT, Uehara T. How bacteria consume their own exoskeletons (turnover and recycling of cell wall peptidoglycan). Microbiol Mol Biol Rev (2008) 72:211-27. doi:10. 1128/MMBR.00027-07

79. Uehara T, Bernhardt TG. More than just lysins: peptidoglycan hydrolases tailor the cell wall. Curr Opin Microbiol (2011) 14:698-703. doi:10.1016/j.mib.2011.10.003

80. Clarke TB, Davis KM, Lysenko ES, Zhou AY, Yu Y, Weiser JN. Recognition of peptidoglycan from the microbiota by Nod 1 enhances systemic innate immunity. Nat Med (2010) 16:228-31. doi:10.1038/ nm.2087

81. Hasegawa M, Yang K, Hashimoto M, Park JH, Kim YG, Fujimoto $\mathrm{Y}$, et al. Differential release and distribution of Nod1 and Nod2 immunostimulatory molecules among bacterial species and environments. J Biol Chem (2006) 281:29054-63. doi:10.1074/jbc.M602638200

82. Davis KM, Weiser JN. Modifications to the peptidoglycan backbone help bacteria to establish infection. Infect Immun (2011) 79:562-70. doi:10.1128/IAI.00651-10

83. Clarke TB, Weiser JN. Intracellular sensors of extracellular bacteria. Immunol Rev (2011) 243:9-25. doi:10.1111/j.1600-065X.2011. 01039.x

84. Lee J, Tattoli I, Wojtal KA Vavricka SR, Philpott DJ, Girardin SE. pH-dependent internalization of muramyl peptides from early endosomes enables Nod1 and Nod2 signaling. J Biol Chem (2009) 284:23818-29. doi:10.1074/jbc.M109.033670

85. Marina-Garcia N, Franchi L, Kim YG, Hu Y, Smith DE, Boons GJ, et al. Clathrin- and dynamindependent endocytic pathway regulates muramyl dipeptide internalization and NOD2 activation. J Immunol (2009) 182:4321-7. doi: 10.4049/jimmunol.0802197

86. Deshmukh HS, Hamburger JB, Ahn SH, McCafferty DG, Yang SR, Fowler VG Jr. Critical role of NOD2 in regulating the immune response to Staphylococcus aureus. Infect Immun (2009) 77:1376-82. doi:10.1128/IAI.00940-08

87. Dharancy S, Body-Malapel M, Louvet A, Berrebi D, Gantier E, Gosset P, et al. Neutrophil migration during liver injury is under 
nucleotide-binding oligomerization domain 1 control. Gastroenterology (2010) 138:1546-56. doi: 10.1053/j.gastro.2009.12.008

88. Smith DE, Clemencon B, Hediger MA. Proton-coupled oligopeptide transporter family SLC15: physiological, pharmacological and pathological implications. $\mathrm{Mol}$ Aspects Med (2013) 34:323-36. doi:10.1016/j.mam.2012.11.003

89. Swaan PW, Bensman T, Bahadduri PM, Hall MW, Sarkar A, Bao $\mathrm{S}$, et al. Bacterial peptide recognition and immune activation facilitated by human peptide transporter PEPT2. Am J Respir Cell Mol Biol (2008) 39:536-42. doi:10. 1165/rcmb.2008-0059OC

90. Sasawatari S, Okamura T, Kasumi E, Tanaka-Furuyama K, YanobuTakanashi R, Shirasawa S, et al. The solute carrier family 15A4 regulates TLR9 and NOD1 functions in the innate immune system and promotes colitis in mice. Gastroenterology (2011) 140:1513-25. doi: 10.1053/j.gastro.2011.01.041

91. Vavricka SR, Musch MW, Chang JE, Nakagawa Y, Phanvijhitsiri K, Waypa TS, et al. hPepT1 transports muramyl dipeptide, activating NF-kappaB and stimulating IL-8 secretion in human colonic Caco2/bbe cells. Gastroenterology (2004) 127:1401-9. doi:10.1053/j. gastro.2004.07.024

92. Charriere GM, Ip WE, Dejardin S, Boyer L, Sokolovska A, Cappillino MP, et al. Identification of Drosophila Yin and PEPT2 as evolutionarily conserved phagosome-associated muramyl dipeptide transporters. J Biol Chem (2010) 285:20147-54. doi:10.1074/jbc.M110.115584

93. Ingersoll SA, Ayyadurai S, Charania MA, Laroui H, Yan Y, Merlin D. The role and pathophysiological relevance of membrane transporter PepT1 in intestinal inflammation and inflammatory bowel disease. Am J Physiol Gastrointest Liver Physiol (2012) 302:G484-92. doi:10.1152/ajpgi.00477.2011

94. Coffman RL, Sher A, Seder RA. Vaccine adjuvants: putting innate immunity to work. Immunity (2010) 33:492-503. doi:10.1016/j. immuni.2010.10.002

95. Freund J, Casals J, Hosmer E. Sensitization and antibody formation after injection of tubercle Bacilli and paraffin oil. Exp Biol Med (1937) 37:509-13. doi:10. 3181/00379727-37-9625

96. Foss DL, Murtaugh MP. Mechanisms of vaccine adjuvanticity at mucosal surfaces. Anim Health Res Rev (2000) 1:3-24. doi:10.1017/ S1466252300000025

97. Adam A, Petit JF, Lefrancier P, Lederer E. Muramyl peptides. Chemical structure, biological activity and mechanism of action. Mol Cell Biochem (1981) 41:27-47.

98. Kobayashi KS, Chamaillard M, Ogura Y, Henegariu O, Inohara N, Nunez G, et al. Nod2-dependent regulation of innate and adaptive immunity in the intestinal tract. Science (2005) 307:731-4. doi:10. 1126/science. 1104911

99. Magalhaes JG, Fritz JH, Le Bourhis L, Sellge G, Travassos LH, Selvanantham T, et al. Nod2dependent Th2 polarization of antigen-specific immunity. $J$ Immunol (2008) 181:7925-35.

100. Shenderov K, Barber DL, MayerBarber KD, Gurcha SS, Jankovic D, Feng CG, et al. Cord factor and peptidoglycan recapitulate the Th17-promoting adjuvant activity of mycobacteria through mincle/CARD9 signaling and the inflammasome. J Immunol (2013) 190:5722-30. doi:10.4049/ jimmunol.1203343

101. Fritz JH, Le Bourhis L, Sellge G, Magalhaes JG, Fsihi H, Kufer TA, et al. Nod1-mediated innate immune recognition of peptidoglycan contributes to the onset of adaptive immunity. Immunity (2007) 26:445-59. doi:10.1016/j.immuni. 2007.03.009

102. Divangahi M, Mostowy S, Coulombe F, Kozak R, Guillot L, Veyrier F, et al. NOD2-deficient mice have impaired resistance to Mycobacterium tuberculosis infection through defective innate and adaptive immunity. J Immunol (2008) 181:7157-65.

103. Davis KM, Nakamura S, Weiser JN. Nod2 sensing of lysozymedigested peptidoglycan promotes macrophage recruitment and clearance of $S$. pneumoniae colonization in mice. $J$ Clin Invest (2011) 121:3666-76. doi:10.1172/JCI57761

104. Geddes K, Rubino SJ, Magalhaes JG, Streutker C, Le Bourhis L, Cho JH, et al. Identification of an innate $\mathrm{T}$ helper type 17 response to intestinal bacterial pathogens. Nat Med (2012) 17:837-44. doi:10. 1038/nm.2391

105. Magalhaes JG, Rubino SJ, Travassos LH, Le Bourhis L, Duan W, Sellge G, et al. Nucleotide oligomerization domaincontaining proteins instruct $\mathrm{T}$ cell helper type 2 immunity through stromal activation. Proc Natl Acad Sci U S A (2011) 108:14896-901. doi:10.1073/pnas. 1015063108

106. Le Bourhis L, Magalhaes JG, Selvanantham T, Travassos LH, Geddes K, Fritz JH, et al. Role of Nod1 in mucosal dendritic cells during Salmonella pathogenicity island 1independent Salmonella enterica serovar Typhimurium infection. Infect Immun (2009) 77:4480-6. doi:10.1128/IAI.00519-09

107. Tada H, Aiba S, Shibata K, Ohteki T, Takada H. Synergistic effect of Nod1 and Nod2 agonists with toll-like receptor agonists on human dendritic cells to generate interleukin-12 and T helper type 1 cells. Infect Immun (2005) 73:7967-76. doi:10.1128/ IAI.73.12.7967-7976.2005

108. Chin AI, Dempsey PW, Bruhn K, Miller JF, Xu Y, Cheng G. Involvement of receptor-interacting protein 2 in innate and adaptive immune responses. Nature (2002) 416:190-4. doi:10.1038/416190a

109. Kobayashi K, Inohara N, Hernandez LD, Galan JE, Nunez G, Janeway CA, et al. RICK/Rip2/CARDIAK mediates signalling for receptors of the innate and adaptive immune systems. Nature (2002) 416:194-9. doi:10.1038/416194a

110. Ruefli-Brasse AA, Lee WP, Hurst S, Dixit VM. Rip2 participates in Bcllo signaling and T-cell receptor-mediated NF-kappaB activation. J Biol Chem (2004) 279:1570-4. doi:10.1074/jbc.C300460200

111. Hall HT, Wilhelm MT, Saibil SD, Mak TW, Flavell RA, Ohashi PS. RIP2 contributes to Nod signaling but is not essential for $\mathrm{T}$ cell proliferation, $\mathrm{T}$ helper differentiation or TLR responses. Eur J Immunol (2008) 38:64-72. doi:10.1002/eji. 200737393

112. Nembrini C, Reissmann R, Kopf M, Marsland BJ. Effective T-cell immune responses in the absence of the serine/threonine kinase RIP2. Microbes Infect (2008) 10:522-30. doi:10.1016/j.micinf.2008.01.016

113. Sauer JD, Pereyre S, Archer KA, Burke TP, Hanson B, Lauer P, et al. Listeria monocytogenes engineered to activate the Nlrc4 inflammasome are severely attenuated and are poor inducers of protective immunity. Proc Natl Acad Sci U $S$ A (2011) 108:12419-24. doi:10. 1073/pnas.1019041108

114. Kayamuro H, Yoshioka Y, Abe Y, Arita S, Katayama K, Nomura T, et al. Interleukin-1 family cytokines as mucosal vaccine adjuvants for induction of protective immunity against influenza virus. J Virol (2010) 84:12703-12. doi:10.1128/ JVI.01182-10

115. Kavathas PB, Boeras CM, Mulla MJ, Abrahams VM. Nod1, but not the ASC inflammasome, contributes to induction of ILlbeta secretion in human trophoblasts after sensing of Chlamydia trachomatis. Mucosal Immunol (2013) 6:235-43. doi:10.1038/mi. 2012.63

116. Kayagaki N, Wong MT, Stowe IB, Ramani SR, Gonzalez LC, AkashiTakamura S, et al. Noncanonical inflammasome activation by intracellular LPS independent of TLR4. Science (2013) 341:1246-9. doi:10. 1126/science.1240248

117. Chen GY, Liu M, Wang F, Bertin J, Nunez G. A functional role for Nlrp6 in intestinal inflammation and tumorigenesis. Jimmunol (2011) 186:7187-94. doi:10.4049/ jimmunol.1100412

118. Elinav E, Strowig T, Kau AL, Henao-Mejia J, Thaiss CA, Booth CJ, et al. NLRP6 inflammasome regulates colonic microbial ecology and risk for colitis. Cell (2011) 145:745-57. doi:10.1016/j. cell.2011.04.022

119. Anand PK, Malireddi RK, Lukens JR, Vogel P, Bertin J, Lamkanfi M, et al. NLRP6 negatively regulates innate immunity and host defence against bacterial pathogens. Nature (2012) 488:389-93. doi:10.1038/nature11250

120. Cui J, Zhu L, Xia X, Wang HY, Legras X, Hong J, et al. NLRC5 negatively regulates the NF-kappaB and type I interferon signaling pathways. Cell (2010) 141: 483-96. doi:10.1016/j.cell.2010.03. 040

121. Benko S, Magalhaes JG, Philpott DJ, Girardin SE. NLRC5 limits the activation of inflammatory pathways. J Immunol (2010) 185:1681-91. doi:10.4049/ jimmunol.0903900

122. Neerincx A, Lautz K, Menning $M$, Kremmer E, Zigrino $\mathrm{P}$, Hosel $\mathrm{M}$, et al. A role for the human nucleotide-binding domain, leucine-rich repeatcontaining family member NLRC5 in antiviral responses. $J$ Biol Chem (2010) 285:26223-32. doi:10.1074/jbc.M110.109736

123. Tong Y, Cui J, Li Q, Zou J, Wang HY, Wang RF. Enhanced TLR-induced NF-kappaB signaling and type I interferon responses 
in NLRC5 deficient mice. Cell Res (2012) 22:822-35. doi:10.1038/cr. 2012.53

124. Uehara A, Yang S, Fujimoto Y, Fukase K, Kusumoto S, Shibata $\mathrm{K}$, et al. Muramyldipeptide and diaminopimelic acid-containing desmuramylpeptides in combination with chemically synthesized Toll-like receptor agonists synergistically induced production of interleukin-8 in a NOD2and NOD1-dependent manner, respectively, in human monocytic cells in culture. Cell Microbiol (2005) 7:53-61.

125. Bagchi A, Herrup EA, Warren HS, Trigilio J, Shin HS, Valentine C, et al. MyD88-dependent and
MyD88-independent pathways in synergy, priming, and tolerance between TLR agonists. J Immunol (2007) 178:1164-71.

126. Rescigno M. The intestinal epithelial barrier in the control of homeostasis and immunity. Trends Immunol (2011) 32:256-64. doi: 10.1016/j.it.2011.04.003

127. Sansonetti PJ. War and peace at the intestinal epithelial surface: an integrated view of bacterial commensalism versus bacterial pathogenicity. I Pediatr Gastroenterol Nutr (2008) 46(Suppl 1):E6-7. doi:10.1097/01.mpg. 0000313819.96520.27

128. Vance RE, Isberg RR, Portnoy DA. Patterns of pathogenesis: discrimination of pathogenic and nonpathogenic microbes by the innate immune system. Cell Host Microbe (2009) 6:10-21. doi:10. 1016/j.chom.2009.06.007

Conflict of Interest Statement: The authors declare that the research was conducted in the absence of any commercial or financial relationships that could be construed as a potential conflict of interest.

Received: 26 August 2013; accepted: 07 October 2013; published online: 21 October 2013.

Citation: Ferrand $J$ and Ferrero $R L$ (2013) Recognition of extracellular bacteria by NLRs and its role in the development of adaptive immunity. Front. Immunol. 4:344. doi: 10.3389/fimmu.2013.00344

This article was submitted to Molecular Innate Immunity, a section of the journal Frontiers in Immunology.

Copyright (c) 2013 Ferrand and Ferrero. This is an open-access article distributed under the terms of the Creative Commons Attribution License (CC BY). The use, distribution or reproduction in other forums is permitted, provided the original author(s) or licensor are credited and that the original publication in this journal is cited, in accordance with accepted academic practice. No use, distribution or reproduction is permitted which does not comply with these terms. 